\title{
(6) OPEN ACCESS \\ Key drivers of visual acuity gains in neovascular age-related macular degeneration in real life: findings from the AURA study
}

\author{
Frank G Holz, ${ }_{1}^{1}$ Ramin Tadayoni, ${ }^{2}$ Stephen Beatty, ${ }^{3}$ Alan Berger, ${ }^{4}$ \\ Matteo Giuseppe Cereda, ${ }^{5}$ Philip Hykin, ${ }^{6}$ Giovanni Staurenghi, ${ }^{5}$ Kim Wittrup-Jensen, ${ }^{7}$ \\ Andreas Altemark, ${ }^{7}$ Jonas Nilsson, ${ }^{8}$ Kun Kim, ${ }^{8}$ Sobha Sivaprasad ${ }^{6,9}$
}

\begin{abstract}
- Additional material is published online only. To view please visit the journal online (http://dx.doi.org/10.1136/ bjophthalmol-2015-308166).

${ }^{1}$ Department of Ophthalmology, University of Bonn, Bonn, Germany ${ }^{2}$ Department of Ophthalmology, Hôpital Lariboisière, AP-HP, Université Paris 7-Sorbonne Paris Cité, Paris, France

${ }^{3}$ Department of Ophthalmology, Institute of Eye Surgery, Waterford, Ireland ${ }^{4}$ Department of Ophthalmology and Vision Sciences, University of Toronto, and St Michael's Hospital, Toronto, Ontario, Canada

${ }^{5}$ Department of Biomedical and Clinical Science Luigi Sacco, Luigi Sacco Hospital, University of Milan, Milan, Italy ${ }^{6} \mathrm{NIHR}$ Biomedical Centre for Research in Ophthalmology, Moorfields Eye Hospital, London, UK

${ }^{7}$ Bayer Pharma AG, Berlin, Germany

${ }^{8}$ Mapi Group, Real World Strategy and Analytics, Stockholm, Sweden ${ }^{9}$ Department of Ophthalmology, King's College Hospital, London, UK
\end{abstract}

Correspondence to Sobha Sivaprasad, King's College Hospital, Denmark Hill, London SE5 9RS, UK; senswathi@aol.com

Received 25 November 2015 Revised 4 February 2016 Accepted 28 February 2016 Published Online First 30 March 2016

\section{CrossMark}

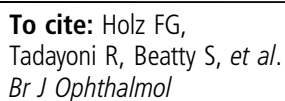

\section{ABSTRACT}

Background/aims To identify predictive markers for the outcomes of anti-vascular endothelial growth factor therapy for neovascular age-related macular degeneration (nAMD).

Methods AURA was a retrospective, observational, multicentre study that monitored the 2-year outcomes following intravitreal ranibizumab treatment in patients with nAMD. Using stepwise regression analysis, we evaluated the association between visual acuity outcomes, baseline characteristics and resource utilisation in order to determine which variables are significantly linked to outcomes in AURA. We also examined the relationship between visual acuity outcomes and number of injections received.

Results Analyses were performed using data from year $1(n=1695)$ and year 2 completers $(n=1184)$. Logistic analysis showed that baseline visual acuity score, age at start of therapy, number of ophthalmoscopies and optical coherence tomography (OCT) (combined) and number of injections (ranibizumab) were significant $(p<0.05)$ prognostic factors for vision maintenance (loss $<15$ letters) or vision gain ( $\geq 15$ letters). Patients who received $>7$ injections (in 1 year) or $>14$ injections (over 2 years) gained more letters and demonstrated greater vision maintenance (loss of $<15$ letters) than patients who received fewer injections. There was a significant $(p<0.05)$ association between number of injections and national reimbursement schemes and OCT.

Conclusions A number of factors that are predictive of treatment outcomes in a real-life setting were identified. Notably, the decline of treatment benefits may be linked to number of injections and a failure to visit clinicians and receive OCT as required. These findings may be helpful in guiding ophthalmologist treatment decisions under limited time and financial constraints.

Trial registration number NCT01447043.

\section{INTRODUCTION}

By 2040, approximately 288 million adults worldwide will have age-related macular degeneration (AMD). ${ }^{1}$ Although it is linked to ageing, the development of neovascular AMD (nAMD) is also associated with vascular endothelial growth factor (VEGF). ${ }^{2}{ }^{3}$ Upregulation of VEGF is implicated in neovascularisation, vascular leakage, vitreous haemorrhage and ultimately blindness. ${ }^{4}$ Increased understanding of the VEGF pathway in nAMD has led to the development and widespread use of anti-VEGF agents, including ranibizumab.
Ranibizumab was approved for the treatment of nAMD based on the findings from two key studies. ${ }^{5}$ Both studies employed a monthly dosing regimen, which can be difficult to implement in clinical practice. Alternative ranibizumab strategies have been investigated but have shown variable efficacy compared with monthly dosing. ${ }^{7-14}$ It is therefore important to monitor the outcomes that might occur with real-life use of ranibizumab. In AURA (a retrospective non-interventional study to assess the effectiveness of existing Anti-vascUlar endothelial growth factor (anti-VEGF) treatment Regimens in patients with wet Age-related macular degeneration (AMD)), a retrospective, observational study, patients with nAMD were diagnosed and treated with ranibizumab by their own physicians in accordance with their usual practice. The mean increase in visual acuity gains after treatment initiation (+4.1 letters at day 120) was not maintained; visual acuity decreased to +2.4 letters at year 1 and to +0.6 letters at year 2 . The mean number of injections received also decreased from 5.0 (year 1) to 2.2 (year 2 ), and there were wide variations between countries. ${ }^{15} 16$

The aim of this regression analysis of the AURA results was to explore the association between the visual acuity outcomes, baseline characteristics and resource utilisation to determine which variables were significantly linked to ranibizumab treatment outcomes. We also examine the relationship between visual acuity outcomes based on the number of injections given over the 2-year period. It is hoped that these analyses will provide a valuable insight into factors affecting treatment outcomes in real-life settings.

\section{METHODS}

Study design and participants

AURA was conducted in eight countries (Canada, France, Germany, Ireland, Italy, the Netherlands, the UK and Venezuela) ${ }^{15}$ from January 2009 to October 2012 (end of data collection). The primary objective of AURA was to monitor the changes in visual acuity during the first year (until day 360) and second year (until day 720) after the start of ranibizumab treatment in real-life, clinical practice settings.

Patients who were diagnosed with nAMD and given ranibizumab by their physician from 1 January 2009 to 31 August 2009 were eligible, and those who had $>1$ postbaseline assessment of visual acuity were analysed (efficacy analysis set). 
Patients with follow-up data for at least 1 and 2 years after the first injection (first-year and second-year completers) were also documented. Patients who switched to bevacizumab or pegaptanib also remained in the study. The mean change in visual acuity was measured using Early Treatment Diabetic Retinopathy Study letters or Snellen, and was converted to a standardised visual acuity score (letter count). The conversion chart used is provided in the online supplementary table S1 for the primary manuscript. ${ }^{15}$ To account for missing data, mean change in visual acuity was evaluated using a last observation carried forward approach (unadjusted observational data were also recorded for comparison), and the statistical analysis was descriptive. Approval from the relevant independent ethics committees or institutional review boards was received, and written consent was obtained from each patient.

\section{Objectives}

The aims of this article are (1) to explore the association between the visual acuity outcomes (defined as difference in letter count, and gain or loss of letters at years 1 and 2), baseline characteristics and resource utilisation in AURA to determine which variables are significant predictors of ranibizumab treatment outcomes, and (2) to examine the relationship between visual acuity outcomes based on the number of injections given over the 2-year period.

\section{Analyses}

Regression analyses were performed using StataCorp LP 2007 (Stata Statistical Software: Release V.10, StataCorp LP, College Station, Texas, USA) with the dataset and patient records from the AURA study, which provided information on demography, medical history, injections and visits. Continuous variables (listed in online supplementary table S1) were reported with mean and SD, 95\% CIs and p values. CIs were estimated based on the assumption that data were normally distributed. Categorical variables (listed in online supplementary table S1) were reported as actual values or dummies (eg, for the variable 'sex', the values were 1 for male and 2 for female).

The association between the mean change in visual acuity score (letter count) at years 1 and 2 and the AURA dataset variables was analysed using univariate regression analysis (data not shown). The variables that were significantly associated (at the $5 \%$ significance level) with mean change in letter count were also tested for correlation using the Pearson's correlation test and for normality using distributional diagnostic plots (continuous variables only) prior to further analysis using stepwise multivariate regression. Logistic regression analysis was used to identify the variables that were determinants of vision maintenance (patients who lost $<15$ letters at years 1 and 2 ) and vision gain (patients who gained $\geq 15$ letters at years 1 and 2) (see online supplementary figure $\mathrm{S} 1$ ).

The relationship between the number of injections $(<5,5-7$ and $>7$ injections during year 1 for year 1 completers and $<10$, $10-14$ and $>14$ injections during the 2 -year period for year 2 completers) and subsequent treatment outcomes was also assessed. Tests for differences between injection subgroups were performed using either analysis of variance (for continuous variables that were normally distributed) or $\chi^{2}$ test (for categorical variables).

\section{RESULTS}

\section{Participants}

A total of 2227 patients were included in the efficacy analysis set. The numbers of year 1 and year 2 completers were 1695 and 1184, respectively. Of patients included in the efficacy analysis set $(n=2227)$, a total of 713 ended the study before the last documented visit; the main reason for this was permanent discontinuation of anti-VEGF agent in 349 (15.7\%) patients, which was due to stable disease $(n=110)$, treatment failure $(\mathrm{n}=81)$, fibrosis/atrophic/scarring $(\mathrm{n}=31)$, ocular adverse event $(n=11)$, patient decision $(n=14)$, cost $(n=7)$, systemic adverse event $(n=1)$, death $(n=1)$ and missing/other $(n=93)$.

Many patients received fewer than five injections during year $1(42.1 \% ; n=714 / 1695)$ and fewer than 10 injections during the 2 -year period $(58.9 \% ; n=697 / 1184)$. There were statistically significant differences between injection subgroups in terms of age and baseline visual acuity. The proportion of patients treated under national reimbursement schemes was significantly higher in the group of patients who received $>7$ injections during year 1 or $>14$ injections over the 2 -year period (table 1 ).

\section{Identification of prognostic factors associated with visual acuity outcomes}

The variables that were significantly $(p<0.05)$ associated with letters gained at year 1 in the stepwise multivariate analysis (table 2A) included baseline visual acuity score (coefficient: $-0.35)$, age at start of therapy $(-0.27)$, switching to other treatments (-4.45) and number of ophthalmoscopies and optical coherence tomography (OCT) (0.28), which were combined, as neither alone would be representative as the most common diagnostic and monitoring tool across all countries. These factors explained $16 \%$ of the variation in the dependent variable (letters gained at year 1) based on 1329 observations. Baseline visual acuity score $(-0.42)$, age $(-0.28)$, number of ophthalmoscopies and OCT $(0.13)$ and injections (ranibizumab) (0.32) were significantly $(p<0.05)$ associated with letters gained at year 2 (table 2B), and explained $21 \%$ of the variation in the outcome (based on 968 observations). There was a positive coefficient between number of ophthalmoscopies and OCT or injections (ranibizumab) and letters gained, which suggests that there was a direct linear relationship between them up to the 2-year period cut-off. There was a strong negative effect of switching to other treatments on early letters gained. Age and visual acuity score were slightly negative, which is suggestive of a negative effect of increasing age or initial letter score.

The results of the logistic regression analysis were similar in that baseline visual acuity score (coefficient: 0.97), age at start of therapy (0.97), number of ophthalmoscopies and OCT (1.03) and injections (ranibizumab) (0.94) were all found to be prognostic factors that significantly $(\mathrm{p}<0.05)$ impacted vision maintenance (loss of $<15$ letters) at year 1 (table $3 \mathrm{~A}$ ), but switch to other treatments was not significant in this model. Age, baseline visual acuity score and number of ophthalmoscopies and OCT were also significantly $(p<0.05)$ associated with vision maintenance at year 2 (table $3 \mathrm{~B}$ ), but injections (ranibizumab) did not achieve significance at year 2. Reimbursement type did not achieve statistical significance at year 1 or year 2 , which may have been due to the large CIs reflecting wide standards in clinical practice. A similar limitation was observed when country was included; the CIs were extremely wide.

Age at start of therapy (0.97), baseline visual acuity score (0.95) and number of ophthalmoscopies and OCT (1.03) were significantly $(p<0.05)$ associated with vision gain (gain of $\geq 15$ letters) at year 1 , but injections (ranibizumab) failed to achieve significance (table 4A). Age and baseline visual acuity score were significantly $(\mathrm{p}<0.05)$ associated with vision gain at year 2. Injections (ranibizumab) were also significant in this model, but number of ophthalmoscopies and OCT was not (table 4B). 
Table 1 Patient characteristics for year 1 and year 2 completers according to number of ranibizumab injections received during year 1 $(<5,5-7,>7$ injections) and over the 2 -year period $(<10,10-14,>14$ injections $)$

\begin{tabular}{|c|c|c|c|c|c|c|c|c|}
\hline \multirow[b]{2}{*}{ Injections } & \multicolumn{4}{|c|}{ Year 1} & \multicolumn{4}{|c|}{ Year 2} \\
\hline & $<5$ & $5-7$ & $>7$ & All & $<10$ & $10-14$ & $>14$ & All \\
\hline Patients, $\mathrm{n}$ & 714 & 621 & 360 & 1695 & 697 & 298 & 189 & 1184 \\
\hline \multicolumn{9}{|l|}{ Age at start of therapy (\%), $\S$} \\
\hline$<65$ years & 8 & 6 & 9 & $8 t$ & 8 & 5 & 10 & $7^{*}$ \\
\hline$\geq 65-<75$ years & 20 & 26 & 29 & $24 \dagger$ & 21 & 27 & 30 & $24^{*}$ \\
\hline$\geq 75$ years & 70 & 66 & 60 & $67+$ & 70 & 66 & 58 & $67^{*}$ \\
\hline Age (years), mean & 77.4 & 76.9 & 76.0 & $76.9^{*}$ & 77.3 & 77.2 & 75.6 & $77^{*}$ \\
\hline \multicolumn{9}{|l|}{ Sex $\%$} \\
\hline Male & 37 & 38 & 39 & 38 & 36 & 39 & 42 & 38 \\
\hline Female & 63 & 62 & 61 & 62 & 64 & 61 & 58 & 62 \\
\hline \multicolumn{9}{|l|}{ Reimbursement type (\%),§, } \\
\hline Individual & 12 & 12 & 5 & $11 \ddagger$ & 10 & 7 & 2 & $8 \ddagger$ \\
\hline National standard & 67 & 72 & 85 & $73 \ddagger$ & 70 & 78 & 88 & $75 \ddagger$ \\
\hline Separate contract & 3 & 0 & 0 & $1 \neq$ & 2 & 1 & 0 & $1 \ddagger$ \\
\hline Independent & 14 & 10 & 7 & $11 \ddagger$ & 13 & 10 & 5 & $11 \ddagger$ \\
\hline Patient & 0 & 0 & 0 & $0 \ddagger$ & 0 & 0 & 0 & $0 \ddagger$ \\
\hline Other & 1 & 0 & 0 & $1 \ddagger$ & 1 & 0 & 1 & $1 \ddagger$ \\
\hline Baseline visual acuity score, mean & 58.3 & 57 & 54.1 & $56.9+$ & 57.7 & 58.5 & 53 & $57.2 \dagger$ \\
\hline
\end{tabular}

Reimbursement type and country were not significant with respect to vision gain. The effect of injections (ranibizumab) (ie, significant for vision maintenance at year 1 and vision gain at year 2) may reflect the importance of injections for predicting letter gains later in the course of treatment.

\section{Association between number of injections and visual acuity outcomes}

The proportion of patients who gained $\geq 15$ letters increased with the number of injections given for the year 1 completers (13\% (<5 injections), 20\% (5-7 injections) and 26\% (>7 injections); $\mathrm{p}<0.01)$, and for the year 2 completers $(17 \% \quad(<10$ injections), 20\% (10-14 injections) and 35\% (>14 injections); $\mathrm{p}<0.001$ ) (figure 1). Year 1 completers who received $>7$ injections gained more letters than those with fewer injections: 4.7 versus 2.9 letters (5-7 injections) and 1.7 letters $(<5$ injections) $(\mathrm{p}<0.05)$. Year 2 completers who received $>14$ injections also gained more letters: 7.5 versus 1.5 letters (10-14 injections) and 0.0 letters $(<10$ injections $)(\mathrm{p}<0.001)$. Similarly, the proportion of patients who lost $<15$ letters was $48 \%$ ( $<5$ injections) compared with 62\% (5-7 injections), and 63\% (>7 injections) for the year 1 completers, and 52\% ( $<10$ injections), $61 \%(10-14$ injections) and 67\% (>14 injections) $(\mathrm{p}<0.05)$ for the year 2 completers.

The mean number of ophthalmoscopies and OCT and clinic (treatment) visits was higher in year 1 completers who received

Table 2 Multivariate analysis to determine the prognostic effects of selected variables* on letters gained from baseline at (A) year 1 and (B) year 2 (only significant variables are shown)

\begin{tabular}{|c|c|c|c|c|c|}
\hline & Coefficient & SE & Lower $95 \% \mathrm{Cl}$ & Upper $95 \% \mathrm{Cl}$ & p Value \\
\hline \multicolumn{6}{|l|}{ (A) Variables (year 1) $\dagger$} \\
\hline Switching to other treatments & -4.45 & 1.72 & -7.82 & -1.07 & 0.010 \\
\hline Age at start of therapy & -0.27 & 0.05 & -0.37 & -0.16 & $<0.001$ \\
\hline Baseline visual acuity score & -0.35 & 0.02 & -0.39 & -0.30 & 0.000 \\
\hline Number of ophthalmoscopies and OCT (combined) & 0.28 & 0.06 & 0.16 & 0.40 & $<0.001$ \\
\hline Constant & 40.33 & 4.51 & 31.48 & 49.17 & $<0.001$ \\
\hline \multicolumn{6}{|l|}{ (B) Variables (year 2) } \\
\hline Number of injections (ranibizumab) & 0.32 & 0.11 & 0.12 & 0.53 & 0.002 \\
\hline Number of ophthalmoscopies and OCT (combined) & 0.13 & 0.04 & 0.05 & 0.21 & 0.001 \\
\hline Age at start of therapy & -0.28 & 0.07 & -0.41 & -0.15 & $<0.001$ \\
\hline Baseline visual acuity score & -0.42 & 0.03 & -0.48 & -0.36 & $<0.001$ \\
\hline Constant & 41.32 & 5.86 & 29.83 & 52.81 & $<0.001$ \\
\hline
\end{tabular}

*The selected variables were the ones that were significantly associated with letters gained in the univariate regression analysis, including those that were tested using Pearson's correlation test and those that were tested for normality (continuous variables only), but only those that remained significant in the multivariate analysis are shown.

OCT, optical coherence tomography.

tNumber of observations of the analysis was 1329; F-value: $64.31 ; R^{2}=0.16$.

¥Number of observations of the analysis was 968 ; F-value: $63.02 ; R^{2}=0.21$. 
Table 3 Logistic regression analysis to determine the prognostic effects of selected variables on vision maintenance (loss of $<15$ letters) at (A) year 1 and (B) year 2

\begin{tabular}{|c|c|c|c|c|c|}
\hline & Coefficient & SE & $\begin{array}{l}\text { Lower } \\
95 \% \mathrm{Cl}\end{array}$ & $\begin{array}{l}\text { Upper } \\
95 \% \mathrm{Cl}\end{array}$ & p Value \\
\hline \multicolumn{6}{|l|}{ (A) Variables (year 1) } \\
\hline \multicolumn{6}{|l|}{ Country } \\
\hline Canada & 1.25 & 1.32 & 0.16 & 9.85 & 0.83 \\
\hline France & 0.71 & 0.74 & 0.09 & 5.42 & 0.74 \\
\hline Germany & 0.78 & 0.82 & 0.10 & 6.12 & 0.82 \\
\hline Ireland & 1.66 & 1.86 & 0.19 & 14.91 & 0.65 \\
\hline Italy & 0.91 & 0.94 & 0.12 & 6.91 & 0.93 \\
\hline The Netherlands & 1.22 & 1.27 & 0.16 & 9.40 & 0.85 \\
\hline UK & 1.21 & 1.27 & 0.15 & 9.43 & 0.86 \\
\hline \multicolumn{6}{|l|}{ Reimbursement type } \\
\hline Individual & 0.71 & 0.23 & 0.38 & 1.33 & 0.28 \\
\hline National standard & 0.79 & 0.19 & 0.49 & 1.26 & 0.32 \\
\hline Separate contract & 0.40 & 0.31 & 0.09 & 1.82 & 0.23 \\
\hline Patient & 0.73 & 1.28 & 0.02 & 22.90 & 0.86 \\
\hline Unknown & 1.41 & 0.89 & 0.41 & 4.87 & 0.59 \\
\hline Other & 0.57 & 0.62 & 0.07 & 4.73 & 0.60 \\
\hline Age at start of therapy & 0.97 & 0.01 & 0.95 & 0.98 & $<0.001$ \\
\hline $\begin{array}{l}\text { Baseline visual acuity } \\
\text { score }\end{array}$ & 0.97 & 0.00 & 0.96 & 0.98 & $<0.001$ \\
\hline $\begin{array}{l}\text { Number of injections } \\
\text { (ranibizumab) }\end{array}$ & 0.94 & 0.03 & 0.88 & 0.99 & 0.03 \\
\hline $\begin{array}{l}\text { Switch to other } \\
\text { treatments }\end{array}$ & 0.86 & 0.23 & 0.51 & 1.44 & 0.56 \\
\hline $\begin{array}{l}\text { Number of } \\
\text { ophthalmoscopies and } \\
\text { OCT (combined) }\end{array}$ & 1.03 & 0.02 & 1.00 & 1.06 & 0.03 \\
\hline \multicolumn{6}{|l|}{ (B) Variables (year 2) } \\
\hline \multicolumn{6}{|l|}{ Country } \\
\hline Canada & 0.59 & 0.64 & 0.07 & 5.03 & 0.63 \\
\hline France & 0.86 & 0.92 & 0.11 & 7.02 & 0.89 \\
\hline Germany & 0.60 & 0.66 & 0.07 & 5.16 & 0.65 \\
\hline Ireland & 0.96 & 1.17 & 0.09 & 10.52 & 0.97 \\
\hline Italy & 0.98 & 1.05 & 0.12 & 8.04 & 0.99 \\
\hline The Netherlands & 1.51 & 1.64 & 0.18 & 12.60 & 0.70 \\
\hline UK & 1.17 & 1.28 & 0.14 & 9.97 & 0.89 \\
\hline \multicolumn{6}{|l|}{ Reimbursement type* } \\
\hline Individual & 0.88 & 0.34 & 0.41 & 1.88 & 0.74 \\
\hline National standard & 0.74 & 0.21 & 0.43 & 1.29 & 0.29 \\
\hline Separate contract & 0.10 & 0.11 & 0.01 & 0.93 & 0.04 \\
\hline Unknown & 0.63 & 0.53 & 0.12 & 3.23 & 0.58 \\
\hline Other & 0.42 & 0.48 & 0.04 & 3.94 & 0.45 \\
\hline Age at start of therapy & 0.96 & 0.01 & 0.94 & 0.98 & $<0.001$ \\
\hline $\begin{array}{l}\text { Baseline visual acuity } \\
\text { score }\end{array}$ & 0.97 & 0.01 & 0.96 & 0.97 & $<0.001$ \\
\hline $\begin{array}{l}\text { Number of monitoring } \\
\text { visits }\end{array}$ & 0.97 & 0.02 & 0.94 & 1.01 & 0.13 \\
\hline $\begin{array}{l}\text { Number of injections } \\
\text { (ranibizumab) }\end{array}$ & 1.00 & 0.02 & 0.97 & 1.04 & 0.85 \\
\hline $\begin{array}{l}\text { Number of } \\
\text { ophthalmoscopies and } \\
\text { OCT (combined) }\end{array}$ & 1.02 & 0.01 & 1.00 & 1.04 & 0.02 \\
\hline
\end{tabular}

${ }^{*}$ Reimbursement patient category dropped because of colinearity. $\mathrm{OCT}$, optical coherence tomography.

more injections (see online supplementary figure S2a). Mean number of OCT was 4.4 ( $<5$ injections), 5.6 (5-7 injections) and 6.2 ( $>7$ injections) $(\mathrm{p}<0.001)$, and mean number of ophthalmoscopies was 4 (<5 injections), 5.4 (5-7 injections) and 5.7
Table 4 Logistic regression to determine the prognostic effects of selected variables on vision gain (gain of $\geq 15$ letters) at (A) year 1 and (B) year 2

\begin{tabular}{|c|c|c|c|c|c|}
\hline & Coefficient & SE & $\begin{array}{l}\text { Lower } \\
95 \% \mathrm{Cl}\end{array}$ & $\begin{array}{l}\text { Upper } \\
95 \% \mathrm{Cl}\end{array}$ & p Value \\
\hline \multicolumn{6}{|l|}{ (A) Variables (year 1) } \\
\hline \multicolumn{6}{|l|}{ Country } \\
\hline Canada & 0.61 & 0.82 & 0.05 & 8.44 & 0.72 \\
\hline France & 0.56 & 0.75 & 0.04 & 7.65 & 0.67 \\
\hline Germany & 0.35 & 0.47 & 0.03 & 4.91 & 0.44 \\
\hline Ireland & 0.49 & 0.72 & 0.03 & 8.69 & 0.63 \\
\hline Italy & 0.76 & 1.01 & 0.06 & 10.34 & 0.84 \\
\hline The Netherlands & 0.99 & 1.32 & 0.07 & 13.49 & 0.99 \\
\hline UK & 0.76 & 1.02 & 0.06 & 10.52 & 0.84 \\
\hline \multicolumn{6}{|l|}{ Reimbursement type* } \\
\hline Individual & 1.16 & 0.48 & 0.52 & 2.59 & 0.73 \\
\hline National standard & 0.92 & 0.27 & 0.51 & 1.65 & 0.78 \\
\hline Separate contract & 3.32 & 3.09 & 0.54 & 20.55 & 0.20 \\
\hline Unknown & 2.05 & 2.80 & 0.14 & 29.72 & 0.60 \\
\hline Other & 1.16 & 0.48 & 0.52 & 2.59 & 0.73 \\
\hline Age at start of therapy & 0.97 & 0.01 & 0.95 & 0.99 & 0.001 \\
\hline $\begin{array}{l}\text { Baseline visual acuity } \\
\text { score }\end{array}$ & 0.95 & 0.00 & 0.94 & 0.96 & 0.000 \\
\hline $\begin{array}{l}\text { Number of injections } \\
\text { (ranibizumab) }\end{array}$ & 1.05 & 0.04 & 0.99 & 1.12 & 0.12 \\
\hline $\begin{array}{l}\text { Switch to other } \\
\text { treatments }\end{array}$ & 0.91 & 0.32 & 0.46 & 1.80 & 0.79 \\
\hline $\begin{array}{l}\text { Number of } \\
\text { ophthalmoscopies and } \\
\text { OCT (combined) }\end{array}$ & 1.03 & 0.02 & 1.00 & 1.07 & 0.05 \\
\hline \multicolumn{6}{|l|}{ (B) Variables (year 2) } \\
\hline \multicolumn{6}{|l|}{ Country } \\
\hline Canada & 0.67 & 0.83 & 0.06 & 7.55 & 0.75 \\
\hline France & 0.65 & 0.80 & 0.06 & 7.18 & 0.73 \\
\hline Germany & 0.93 & 1.16 & 0.08 & 10.72 & 0.96 \\
\hline Ireland & 0.67 & 0.94 & 0.04 & 10.44 & 0.78 \\
\hline Italy & 0.98 & 1.21 & 0.09 & 11.02 & 0.99 \\
\hline The Netherlands & 1.22 & 1.49 & 0.11 & 13.34 & 0.87 \\
\hline UK & 0.82 & 1.01 & 0.07 & 9.22 & 0.87 \\
\hline \multicolumn{6}{|l|}{ Reimbursement typet } \\
\hline Individual & 0.43 & 0.21 & 0.17 & 1.11 & 0.08 \\
\hline National standard & 0.70 & 0.22 & 0.37 & 1.31 & 0.27 \\
\hline Unknown & 0.30 & 0.31 & 0.04 & 2.26 & 0.25 \\
\hline Other & 3.25 & 4.11 & 0.27 & 38.66 & 0.35 \\
\hline Age at start of therapy & 0.96 & 0.01 & 0.94 & 0.98 & 0.000 \\
\hline $\begin{array}{l}\text { Baseline visual acuity } \\
\text { score }\end{array}$ & 0.95 & 0.01 & 0.94 & 0.96 & 0.000 \\
\hline $\begin{array}{l}\text { Number of monitoring } \\
\text { visits }\end{array}$ & 1.00 & 0.02 & 0.96 & 1.04 & 1.00 \\
\hline $\begin{array}{l}\text { Number of injections } \\
\text { (ranibizumab) }\end{array}$ & 1.05 & 0.02 & 1.00 & 1.09 & 0.03 \\
\hline $\begin{array}{l}\text { Number of } \\
\text { ophthalmoscopies and } \\
\text { OCT (combined) }\end{array}$ & 1.01 & 0.01 & 0.99 & 1.03 & 0.23 \\
\hline
\end{tabular}

*'Patient' category dropped and two observations not used.

†'Separate contract' category dropped and seven observations not used; 'patient' category dropped because of colinearity.

OCT, optical coherence tomography.

( $>7$ injections) $(\mathrm{p}<0.001)$. The mean number of clinic visits was $3.5,6.2$ and $9.5(\mathrm{p}<0.001)$, respectively, for the year 1 completers. In contrast, monitoring visits, and use of indocyanine green angiography or fluorescein angiography decreased with increased injection frequency. Similar findings were observed 

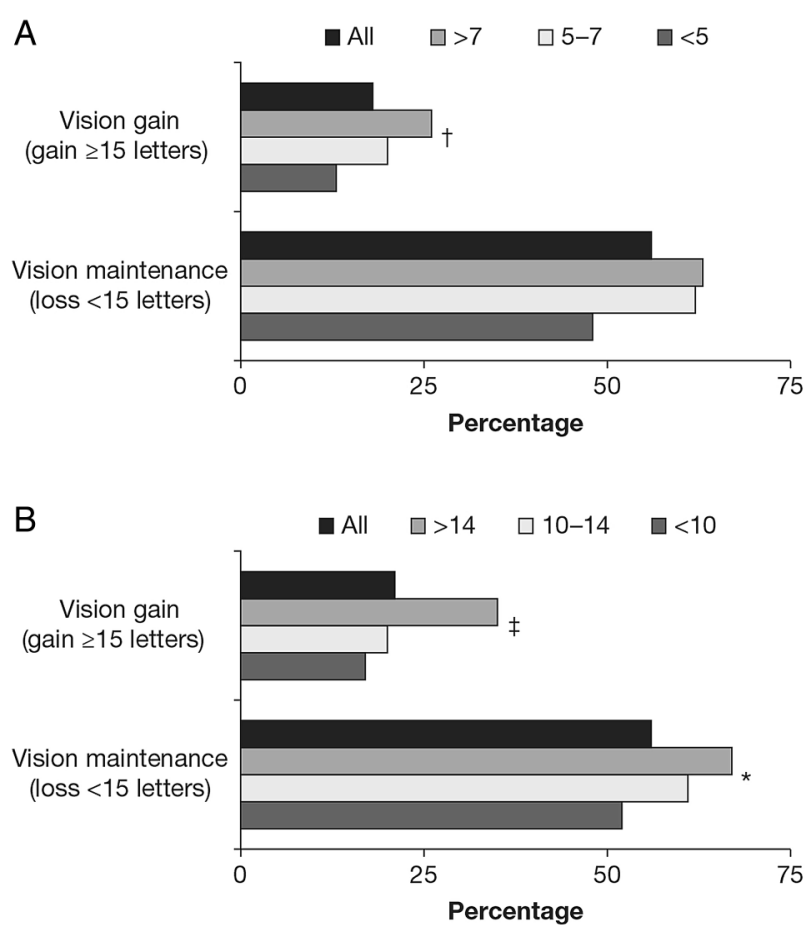

Figure 1 Treatment outcomes for (A) year 1 and (B) year 2 completers according to number of ranibizumab injections received during year $1(<5,5-7,>7$ injections) and over the 2 -year period $(<10$, $10-14,>14$ injections). ${ }^{*} p<0.05 ; t p<0.01 ; \neq p<0.001$ between groups ( $p$ value was derived from analysis of variance for continuous variables and $\chi^{2}$ test for categorical variables).

in year 2 completers (see online supplementary figure S2b). Mean number of OCT was 9.6 (<10 injections), 12.6 (10-14 injections) and 12.7 (>14 injections) $(\mathrm{p}<0.001)$. Mean number of ophthalmoscopies was 8.3 (<10 injections), 10.4 (10-14 injections) and 10.7 (>14 injections) $(\mathrm{p}<0.001)$. Mean number of clinic visits was $6.2,12.4$ and $18.5(\mathrm{p}<0.001)$.

\section{DISCUSSION}

The effectiveness of ranibizumab observed in AURA ${ }^{15}$ was significantly lower than that achieved in clinical (although not observational) studies that employed fixed monthly treatment or an individualised (pro re nata) regimen based on fixed monthly monitoring visits. In the Comparison of AMD Treatment Trial (CATT), the mean change in visual acuity was +6.8 letters at year 1 and +6.7 letters at year 2 with ranibizumab pro re nata, and the mean number of injections was 12.6 over the 2-year period. ${ }^{12}$

In the current analysis, patients who received $>7$ injections in year 1 or $>14$ injections over 2 years gained more letters and demonstrated greater vision maintenance (loss of $<15$ letters) than patients who received $<5$ or $5-7$ injections in year 1 or $<10$ or $10-14$ injections over 2 years. Of particular interest was the significant association between higher number of injections and national reimbursement schemes and use of OCT, and also the increase in the number of clinic (treatment) visits compared with a decrease in the number of monitoring visits over the same timeframe.

Baseline visual acuity score, age at start of therapy, number of ophthalmoscopies and OCT (combined) and ranibizumab injections were shown to be prognostic factors associated with treatment outcomes. The results from these analyses support the findings from the PIER study, which found that visual tests such as OCT were predictive of treatment success following ranibizumab use. ${ }^{17}$ It is possible that a number of other potential factors, which were not included in this analysis, could also affect the outcome, including comorbidities (particularly depression), poor access to treatments and facilities and limited transport to clinic visits- which could be linked to age.

Although no individual country was associated with a significant effect for visual acuity outcomes in the logistic regression models (possibly due to wide CIs as a result of numerous centres being included from each country), the UK did achieve the highest visual acuity benefits at year 1 (6.0) and year 2 (4.1). The mean numbers of all visits were 10.4 (year 1 ) and 8.0 (year 2 ), and the mean numbers of injections were 5.8 (year 1) and 3.2 (year 2). ${ }^{15} 16$ It is possible that more timely monitoring, free access to National Health Service monitoring (which also includes OCT) and treatment, and high-quality control by payers (ie, adherence to protocols for frequent monitoring) could account for the UK situation. Some of these external factors were not considered in this analysis.

The analysis is also subject to a number of other limitations. It was unclear whether the better outcomes in patient receiving more injections was due to increased injection frequency or other factors that were also significantly different among the groups, such as baseline visual acuity score and age. Regression analysis methods (based on observational data) are also associated with a number of limitations. The models use a number of assumptions, including no adjustment for change in factors such as OCT usage since AURA was undertaken. The data were recorded from 2009 to 2012, when the risks of underdosing were not as well understood as they are today, and this may affect the extrapolation of the results. They are still relevant for countries and practices that still have limited resources for regular monitoring and injections; however, some countries may employ better regimens due to increased awareness of the risk of undertreatment, including the wider use of treat-and-extend regimens aimed at reducing the number of visits, which may improve adherence and, thus, outcomes. Combining the ophthalmoscopy and OCT data has limitations, as monitoring with ophthalmoscopy is not a primary measure for helping with retreatment decisions, but this was done because of differences in the most common diagnostic used by country. There may also be bias in patients who were enrolled in the study (towards responders); however, discontinuation resulted from a number of factors seen in routine clinical practice. Although there is a lack of adequate adjustment for multicollinearity, it is a robust method, and we have employed a stepwise approach, taking into consideration any correlation and adjustment for distribution of data.

In conclusion, a number of factors that may be predictive of treatment outcomes, in a real-life setting, were identified, including age, baseline visual acuity score, number of injections and regular monitoring. This analysis also suggests that a compromised treatment regimen, in which patients are not adequately monitored and do not receive individually optimised treatment, will result in inferior treatment outcomes and, hence, impact the effective management of nAMD.

Acknowledgements Medical writing assistance was provided by S Phillips, PhD, from PAREXEL.

Contributors FGH, RT, SB, AB, MGC, PH, GS and SS are members of the Global Steering/Publication Committee for the AURA study and were involved in provision of patient/data acquisition, data analysis, data review and interpretation. AA was involved in the design of the AURA study and protocol, and participated in discussions on the interpretation of the data. KW-J, JN and KK were involved in the design, data collection, analysis and interpretation of the regression analyses of AURA. All authors provided critical review of the manuscript and approved the final version for publication. 
Funding The study was funded by Bayer HealthCare Pharmaceuticals. The sponsor or funding organisation participated in the design and conduct of the study, data collection, data management, data analysis, interpretation of the data and preparation of manuscript.

Competing interests FGH is a consultant to Acucela, Genentech, Novartis, Bayer HealthCare, Alcon, OPTOS, Heidelberg Engineering, Carl Zeiss Meditec, Allergan and Pfizer, and has received grants from OPTOS, Heidelberg Engineering, Carl Zeiss Meditec, Alcon, Genentech, Bayer HealthCare and Novartis. RT is a board member of Alcon, Novartis, Allergan, Bausch \& Lomb, Pfizer, Alimera, Bayer HealthCare and FCl-Zeiss, and a consultant for Allergan, DORC, Alcon, Novartis, Takeda, Bausch \& Lomb and FCl-Zeiss. He has received payment for lectures from Alcon, Bausch \& Lomb, Novartis, Allergan, Pfizer, Takeda, Bayer HealthCare and Alimera, and has received payment for development of educational presentations from Bausch \& Lomb, Novartis, Zeiss, Sony, Alcon and Allergan. He has also received support for meeting expenses (travel and accommodation) from Alcon, Novartis, Allergan, Bausch \& Lomb, Pfizer, Bayer HealthCare, DORC, Takeda, Servier and Alimera. SB is a consultant and board member for Bayer HealthCare, and has received support for travel to meetings and fees for participation in review activities from Bayer HealthCare. AB has received honoraria from Bayer HealthCare, Novartis, Alcon and Allergan. Institutional research funding support was received from Bayer HealthCare, Novartis and Alcon. Fellowship support funding was received from Alcon, Bayer HealthCare, Novartis and Woodgreen Pharmacy. He has received travel fees and speaker fees and participated in advisory boards for Bayer HealthCare and Novartis. MGC is a consultant to Bayer HealthCare and has received support for travel to meetings from Bayer HealthCare and Alcon. PH has received grants from Bayer HealthCare, Allergan and Novartis, and acts as a consultant to Bayer HealthCare, Novartis and Allergan. He has also received support for travel to meetings, for participation in review activities and provision of writing assistance, medicines, equipment or administrative support from Bayer HealthCare, has received payment for lectures from Allergan and Novartis and has received support for conference attendance. GS acts as a consultant to Novartis, Bayer HealthCare, Allergan, Genentech, Roche, Heidelberg Engineering and Alcon. He has also received support for travel to meetings from Bayer HealthCare, Centervue, Heidelberg Engineering and Novartis. He has received payment for lectures from Zeiss, and is a patent holder in conjunction with Ocular Instruments, Inc. He has received payment for development of educational presentations for Roche. SS has received research grants from Bayer HealthCare, Novartis and Allergan that were paid to her institution. She has received travel fees and speaker fees and has participated in advisory boards for Bayer HealthCare, Novartis and Allergan, and has participated in an advisory board meeting for Roche. AA and KW-J are employees of Bayer HealthCare. JN and KK are employees of Mapi Group, who were contracted by Bayer HealthCare to perform the analyses.

Patient consent Obtained.

Ethics approval Country IEC and IRB.

Provenance and peer review Not commissioned; externally peer reviewed.

Open Access This is an Open Access article distributed in accordance with the Creative Commons Attribution Non Commercial (CC BY-NC 4.0) license, which permits others to distribute, remix, adapt, build upon this work non-commercially, and license their derivative works on different terms, provided the original work is properly cited and the use is non-commercial. See: http://creativecommons.org/ licenses/by-nc/4.0/

\section{REFERENCES}

1 Wong WL, Su X, Li X, et al. Global prevalence of age-related macular degeneration and disease burden projection for 2020 and 2040: a systematic review and meta-analysis. Lancet Glob Health 2014;2:e106-16.

2 Ablonczy Z, Dahrouj M, Marneros AG. Progressive dysfunction of the retinal pigment epithelium and retina due to increased VEGF-A levels. FASEB J 2014;28:2369-79.

3 Sharma K, Sharma NK, Anand A. Why AMD is a disease of ageing and not of development mechanisms and insights. Front Aging Neurosci 2014;6:151.

4 Ho QT, Kuo CJ. Vascular endothelial growth factor: biology and therapeutic applications. Int I Biochem Cell Biol 2007;39:1349-57.

5 Brown DM, Kaiser PK, Michels M, et al. Ranibizumab versus verteporfin for neovascular age-related macular degeneration. N Engl J Med 2006;355: 1432-44.

6 Rosenfeld PJ, Brown DM, Heier JS, et al. Ranibizumab for neovascular age-related macular degeneration. N Engl J Med 2006;355:1419-31.

7 Berg K, Pedersen TR, Sandvik L, et al. Comparison of ranibizumab and bevacizumab for neovascular age-related macular degeneration according to LUCAS treat-and-extend protocol. Ophthalmology 2015;122: $146-52$.

8 Boyer DS, Heier JS, Brown DM, et al. A phase IIIb study to evaluate the safety of ranibizumab in subjects with neovascular age-related macular degeneration. Ophthalmology 2009;116:1731-9.

9 Busbee BG, Ho AC, Brown DM, et al. Twelve-month efficacy and safety of $0.5 \mathrm{mg}$ or $2.0 \mathrm{mg}$ ranibizumab in patients with subfoveal neovascular age-related macular degeneration. Ophthalmology 2013;120:1046-56.

10 Chakravarthy U, Harding SP, Rogers CA, et al. Alternative treatments to inhibit VEGF in age-related choroidal neovascularisation: 2-year findings of the IVAN randomised controlled trial. Lancet 2013;382:1258-67.

11 Hariprasad SM, Morse LS, Shapiro $H$, et al. Fixed monthly versus less frequent ranibizumab dosing and predictors of visual response in exudative age-related macular degeneration. J Ophthalmol 2012;2012:690641.

12 Martin DF, Maguire MG, Fine SL, et al. Ranibizumab and bevacizumab for treatment of neovascular age-related macular degeneration: two-year results. Ophthalmology 2012;119:1388-98.

13 Regillo CD, Brown DM, Abraham P, et al. Randomized, double-masked, sham-controlled trial of ranibizumab for neovascular age-related macular degeneration: PIER study year 1. Am J Ophthalmol 2008;145: 239-248.

14 Schmidt-Erfurth U, Eldem B, Guymer R, et al. Efficacy and safety of monthly versus quarterly ranibizumab treatment in neovascular age-related macular degeneration: the EXCITE study. Ophthalmology 2011;118:831-9.

15 Holz FG, Tadayoni R, Beatty S, et al. Multi-country real-life experience of anti-vascular endothelial growth factor therapy for wet age-related macular degeneration. Br J Ophthalmol 2015;99:220-6.

16 Ziemssen $\mathrm{F}$, Eter $\mathrm{N}$, Fauser $\mathrm{S}$, et al. [Retrospective investigation of anti-VEGF treatment reality and effectiveness in patients with neovascular age-related macular degeneration (AMD) in Germany: treatment reality of ranibizumab for neovascular AMD in Germany]. Ophthalmologe 2015;112:246-54.

17 Brown DM, Tuomi L, Shapiro H. Anatomical measures as predictors of visual outcomes in ranibizumab-treated eyes with neovascular age-related macular degeneration. Retina 2013;33:23-34. 